\title{
IL-17A promotes the proliferation of human nasopharyngeal carcinoma cells through p300-mediated Akt1 acetylation
}

\author{
KEMIN CAI $^{1 *}$, BING WANG $^{2 *}$, HONGMEI DOU $^{1 *}$, RONGLAN LUAN $^{1 *}$, XUELI BAO $^{1 *}$ and JIUSHENG CHU ${ }^{1}$ \\ ${ }^{1}$ Department of Otorhinolaryngology Head and Neck Surgery, Taizhou People's Hospital, Taizhou, \\ Jiangsu 225300; ${ }^{2}$ Department of Neurosurgery, Suzhou Kowloon Hospital Affiliated with \\ Shanghai Jiao Tong University School of Medicine, Suzhou, Jiangsu 215021, P.R. China
}

Received July 21, 2015; Accepted February 7, 2017

DOI: $10.3892 / \mathrm{ol} .2017 .5962$

\begin{abstract}
Interleukin(IL)-17A is a Thelper(Th)17 cell-secreted cytokine that is able to induce various inflammatory responses. There is emerging evidence that IL-17A is generated in the cancer microenvironment of human nasopharyngeal carcinoma (NPC). However, the role of IL-17A in NPC remains unclear. Thus, the present study aimed to examine the direct influence of IL-17A stimulation on the proliferation of human NPC cells and identify the underlying molecular mechanisms. Furthermore, E1A binding protein p300 (p300)-mediated AKT serine/threonine kinase 1 (Akt1) acetylation and its role in regulating the proliferation of NPC cells was investigated. The results of the current study demonstrated that IL-17A stimulation in vitro increased the proliferation of human NPC cells. Furthermore, Akt1 acetylation was identified to be enhanced in human NPC cells induced by IL-17A. Additionally, p300 induction was demonstrated to be required for Akt1 acetylation in human NPC cells following exposure to IL-17A. Functionally, p300-mediated Aktl acetylation contributed to the proliferation of human NPC cells stimulated by IL-17A. In conclusion, the results of the present demonstrate a novel activity of IL-17A that promotes human NPC cell proliferation via p300-mediated Akt1 acetylation. This may provide a potential strategy for the treatment of patients with NPC through the inhibition of IL-17A or its receptors.
\end{abstract}

\section{Introduction}

Nasopharyngeal carcinoma (NPC) is a common tumor that occurs in the head and neck. NPC is caused by a

Correspondence to: Dr Jiusheng Chu, Department of Otorhinolaryngology Head and Neck Surgery, Taizhou People's Hospital, 210 Yingchun Road, Taizhou, Jiangsu 225300, P.R. China

E-mail: chujiushengsz@sina.com

*Contributed equally

Key words: nasopharyngeal carcinoma, proliferation, AKT serine/threonine kinase 1, interluekin-17A, acetylation, E1A binding protein $\mathrm{p} 300$ combination of factors including viral, environmental and heredity reasons (1-5). However, its pathogenesis remains unclear. Previous studies have demonstrated that $\mathrm{T}$ helper (Th)17 cells and Th17 cell-secreted interleukin (IL)-17A in the tumor microenvironment leads to a significant increase in tumor progression of various types of cancer, including lung, intestinal and brain cancer (6-8). Furthermore, it has been reported that exogenous IL-17A may significantly promote cell migration and invasion in NPC cells (9); however, the effect of IL-17A on NPC cells and its underlying mechanism remain unclear.

It is well-known that the activation of signaling pathways is involved in various types of carcinoma (10-13). Among these, AKT serine/threonine kinase 1 (Akt1) activation has been revealed to serve an essential role in numerous types of carcinoma, including NPC (14-21). Thus, targeting aberrant Akt1 signaling may provide an effective and novel strategy for the treatment of patients with NPC. Despite the fact that Akt1 activation is common in NPC, the mechanism of this activation has not been elucidated.

Increasing evidence suggests that modification of protein acetylation is involved in the regulation of various cellular biological events, including cell proliferation, apoptosis, autophagy and inflammatory responses (22-26). It has been reported that Akt1 acetylation promotes Akt1 phosphorylation and enhances the proliferation of human glioblastoma cells (27); however, the role of Akt1 acetylation in regulating Akt1 activation in NPC remains unclear.

In the current study, the role of IL-17A in the proliferation of human NPC cells was evaluated in vitro. E1A binding protein p300 (p300)-mediated Akt1 acetylation and its role in the regulation of NPC cell proliferation were also investigated.

\section{Materials and methods}

Reagents. Recombinant human IL-17A was obtained from R\&D Systems, Inc. (Minneapolis, MN, USA). Monoclonal antibodies against human CREB-binding protein (CBP; cat. no. sc-7300; dilution, 1:400), p300 (cat. no. sc-48343; dilution, 1:500) and p300/CBP-associated factor (PCAF; cat. no. sc-13124; dilution, 1:500) were purchased from Santa Cruz Biotechnology, Inc. (Dallas, TX, USA). Monoclonal antibodies against human $\beta$-actin (cat. no. 4970; dilution, 1:1,000), total 
Akt1 (t-Akt1; cat. no. 2938; dilution, 1:1,000), phosphorylated (p)-Akt-Thr ${ }^{308}$ (cat. no. 13038; dilution, 1:1,000), p-Akt-Ser ${ }^{473}$ (cat. no. 4060; dilution, 1:2,000) and acetylated-lysine (cat. no. 9681; dilution, 1:1,000) were purchased from Cell Signaling Technology, Inc. (Danvers, MA, USA). Horseradish peroxidase-conjugated anti-rabbit (cat. no. 7074; dilution, 1:3,000), anti-mouse (cat. no. 7076; dilution, 1:3,000) and anti-rabbit (Conformation Specific; cat. no. 5127; dilution, 1:2,000) immunoglobulin $\mathrm{G}(\mathrm{IgG})$ secondary antibodies, blocking skim-milk and the enhanced chemiluminescence detection system were purchased from Cell Signaling Technology, Inc. Polyvinylidene difluoride membranes were obtained from EMD Millipore (Billerica, MA, USA). Anti-IL-17AR neutralizing antibody (cat. no. ab92608) and iso control IgG (cat. no. ab81032) were purchased from Abcam (Cambridge, UK). The plasmids of pGCsi-U6/neo/green fluorescent protein (GFP) were obtained from Shanghai Genkan Biotechnology Co., Ltd. (Shanghai, China). The pcDNA3.1 vector and Lipofectamine ${ }^{\circledR} 2000$ were obtained from Invitrogen (Thermo Fisher Scientific, Inc., Waltham, MA, USA). A QIAprep spin miniprep kit was obtained from Qiagen GmbH (Hilden, Germany). The Cell Counting Kit-8 (CCK-8) assay was purchased from Dojindo Molecular Technologies, Inc. (Kumamoto, Japan).

Cell culture. The human NPC cell line C666-1 was obtained from the American Type Culture Collection (Manassas, VA, USA). Cells were cultured in RPMI-1640 medium (Thermo Fisher Scientific, Inc.) supplemented with $10 \%$ (v/v) fetal bovine serum from Gibco (Thermo Fisher Scientific, Inc.), $50 \mathrm{U} / \mathrm{ml}$ penicillin and $100 \mathrm{ug} / \mathrm{ml}$ streptomycin (both Invitrogen; Thermo Fisher Scientific, Inc.) at $37^{\circ} \mathrm{C}$ in $5 \% \mathrm{CO}_{2}$.

Cell treatment and study design. Various doses of purified human IL-17A protein $(0,0.001,0.01,0.1,1,10$ and $100 \mathrm{ng} / \mathrm{ml})$ were added into the culture medium of C666-1 NPC cells. Following $48 \mathrm{~h}$ incubation at $37^{\circ} \mathrm{C}$, cellular proliferation was detected using the CCK-8 assay. Next, the cells were incubated with anti-IL-17AR neutralizing antibody $(0.01,0.1$ and $1 \mu \mathrm{g} / \mathrm{ml})$ or iso control $\operatorname{IgG}(0.01,0.1$ and $1 \mu \mathrm{g} / \mathrm{ml})$ at $37^{\circ} \mathrm{C}$ for $30 \mathrm{~min}$, and subsequently incubated with IL-17A (10 ng/ml) or PBS solvent control at $37^{\circ} \mathrm{C}$ for $48 \mathrm{~h}$. Subsequently, cellular proliferation was detected. The levels of Akt1 phosphorylation at Thr308 and Ser473 sites, as well as Akt1 acetylation were detected in C666-1 cells stimulated with IL-17A (10 ng/ml) or PBS solvent control at $37^{\circ} \mathrm{C}$ for $30 \mathrm{~min}$. Furthermore, the expression of CBP, p300 and PCAF, as well as the interaction of Akt1 with CBP, p300 and PCAF were detected in C666-1 cells stimulated with IL-17A $(10 \mathrm{ng} / \mathrm{ml})$ or PBS solvent control at $37^{\circ} \mathrm{C}$ for $30 \mathrm{~min}$. C666-1 cells were transfected with p300 short hairpin (sh)RNA or control shRNA and cultured at $37^{\circ} \mathrm{C}$ for $48 \mathrm{~h}$, followed by IL-17A stimulation $(10 \mathrm{ng} / \mathrm{ml})$ at $37^{\circ} \mathrm{C}$ for $30 \mathrm{~min}$ or $48 \mathrm{~h}$. Akt1 acetylation and phosphorylation in C666-1 cells were determined at 30 min following IL-17A stimulation, and cellular proliferation was determined at $48 \mathrm{~h}$ following IL-17A stimulation. Finally, Ly294002 $(10 \mu \mathrm{M} / \mathrm{ml})$ or DMSO solvent control were added into the culture medium of C666-1 NPC cells at $30 \mathrm{~min}$ prior to IL-17A stimulation $(10 \mathrm{ng} / \mathrm{ml})$ and the cellular proliferation was detected at $48 \mathrm{~h}$ following IL-17A stimulation.
Generation of overexpression plasmids. The plasmid of pcDNA3.1/Akt1-His was provided by Dr. Lei Shi at The First People's Hospital of Kunshan affiliated to Jiangsu University (Zhenjiang, China).

Construction of (sh)RNA expression plasmids. To silence the p300 gene in human NPC cells, various shRNA sequences were designed against human p300 mRNA (NM_001429.3) by Shanghai Genkan Biotechnology Co., Ltd. The different DNA segments of p300 shRNA were constructed into the plasmids of pGCsi-U6/neo/GFP respectively by Shanghai Genkan Biotechnology Co., Ltd. and the most effective shRNA expression plasmids (5'-GGACAGGTATCAAATCCTC-3') were selected for further functional experiments.

Cellular transfection. NPC cells were transfected with pcDNA3.1/Akt1-His or pGCsi-U6/neo/GFP using Lipofectamine 2000 according to a previously described method (28). Cells were seeded into 6-well plates at a density of $1 \times 10^{5}$ cells/well. Following $24 \mathrm{~h}$ at $37^{\circ} \mathrm{C}, 4 \mu \mathrm{g}$ of plasmid was transfected into each well.

Co-immunoprecipitation experiment. For certain studies, co-immunoprecipitation experiments were performed using an antibody against t-Aktl according to a previously described method (28).

Western blot analysis. Western blot analysis was performed to detect $\beta$-actin, CBP, p300, PCAF, t-Akt1, p-Akt-Thr ${ }^{308}$, p-Akt-Ser ${ }^{473}$ and acetylated-lysine, according to a previously described method (28).

CCK-8 assay. Following each treatment, NPC cells were incubated with CCK- 8 at $37^{\circ} \mathrm{C}$ for $4 \mathrm{~h}$. The formazan product was measured with a microplate reader at a wavelength of $450 \mathrm{~nm}$ and the absorbance was directly proportional to the cell number (29).

Statistical analysis. All statistical analysis was performed using SPSS software (version 11.5; SPSS, Inc., Chicago, IL, USA). All data are presented as the mean \pm standard deviation. The statistical significance of groups was evaluated using one-way analysis of variance with simultaneous multiple comparisons between groups using Bonferroni's correction. $\mathrm{P}<0.05$ was considered to indicate a statistically significant difference.

\section{Results}

IL-17A promotes the proliferation of human NPC cells. Various doses of purified human IL-17A protein $(0,0.001,0.01$, $0.1,1,10$ and $100 \mathrm{ng} / \mathrm{ml}$ ) were added into the culture medium to induce proliferation of C666-1 NPC cells at $37^{\circ} \mathrm{C}$ for $48 \mathrm{hr}$. The proliferation assay demonstrated that IL-17A enhanced the proliferation of C666-1 cells in a dose-dependent manner (Fig. 1A). Compared with the untreated control group, the proliferative activity was significantly increased in the C666-1 cells treated with $0.1 \mathrm{ng} / \mathrm{ml}$ IL-17. Furthermore, the cells were incubated with anti-IL-17AR neutralizing antibody or IgG iso control at $37^{\circ} \mathrm{C}$ for $30 \mathrm{~min}$ and subsequently incubated with 

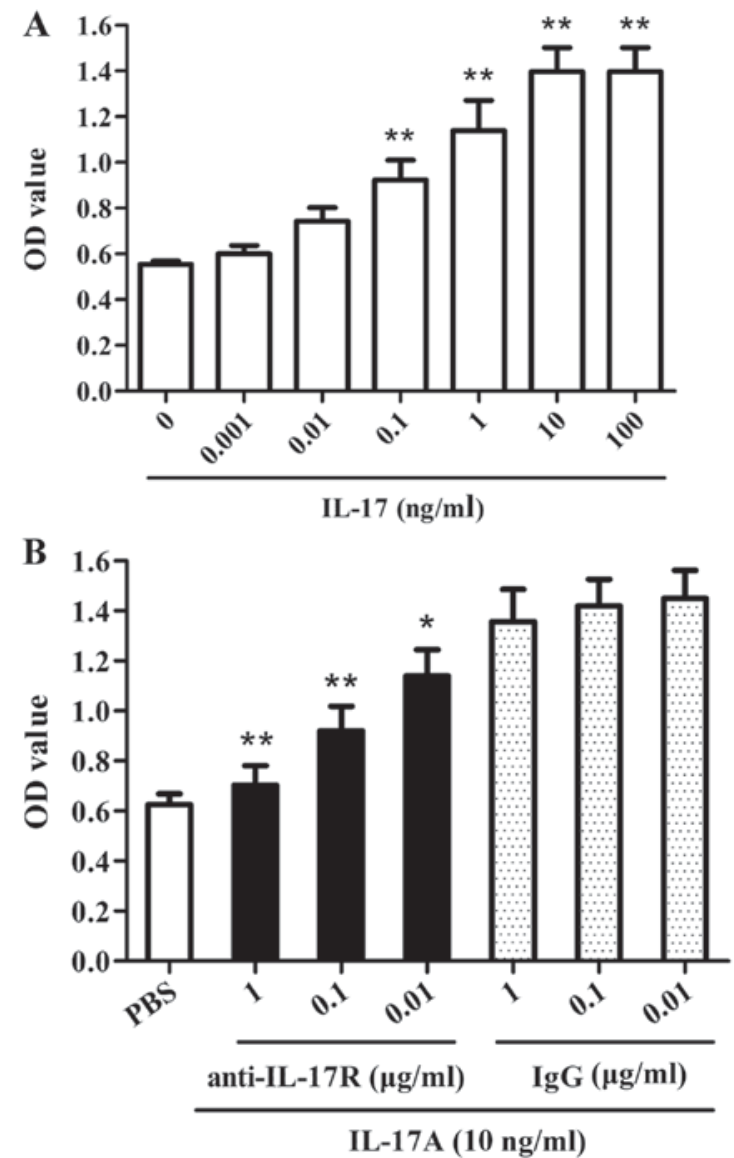

Figure 1. Effect of IL-17A on the proliferation of nasopharyngeal carcinoma C666-1 cells. (A) C666-1 cells were treated with various doses $(0.001-100 \mathrm{ng} / \mathrm{ml})$ of human IL-17A to induce cellular proliferation for $48 \mathrm{~h}$. CCK-8 analysis revealed that IL-17A stimulation enhanced the proliferation of C666-1 cells in a dose-dependent manner in vitro. ${ }^{* *} \mathrm{P}<0.01$ vs. untreated control group. (B) C666-1 cells were incubated with various doses of anti-IL-17AR neutralizing antibody or isotype control $\operatorname{IgG}$ for $30 \mathrm{~min}$, and subsequently cellular proliferation was induced by $10 \mathrm{ng} / \mathrm{ml}$ IL-17A for 48 h. CCK-8 analysis demonstrated that blockade of the IL-17A receptor suppressed the IL-17A-triggered proliferation of C666-1 cells in a dose-dependent manner. ${ }^{*} \mathrm{P}<0.05,{ }^{* *} \mathrm{P}<0.01$ vs. $\mathrm{IgG}+\mathrm{IL}-17 \mathrm{~A}$ group. The data are representative of three independent experiments. All results are represented as the mean \pm standard deviation. IL-17A, interleukin-17A; CCK-8, Cell Counting Kit-8; OD, optical density; IgG, immunoglobulin G.

IL-17A or PBS control at $37^{\circ} \mathrm{C}$ for $48 \mathrm{~h}$. The proliferation assay revealed that blockade of the IL-17A receptor significantly reduced IL-17A-triggered C666-1 cell proliferation compared with the isotype IgG control group (Fig. 1B). These findings indicate that IL-17A is able to promote the proliferation of human NPC cells.

Aktl phosphorylation and acetylation is enhanced in human NPC cells induced by IL-17A. Since Akt1 activation is considered to be involved in human NPC cell proliferation (14-17), the effect of IL-17A stimulation on Akt1 activation was further investigated in NPC cells. It was demonstrated that the levels of Akt1 phosphorylation at $\mathrm{Thr}^{308}$ and $\mathrm{Ser}^{473}$ sites were markedly enhanced in C666-1 cells stimulated by IL-17A for 30 min in vitro compared with the untreated control group (Fig. 2A). It has been reported that the modification of protein acetylation is an important post-transcriptional regulation that may promote Akt1 phosphorylation (27). Therefore, the effect of IL-17A stimulation on Akt1 acetylation was studied in C666-1 cells subsequently. The result revealed that the level of Akt1 acetylation was markedly increased in human NPC cells following stimulation with IL-17A for $30 \mathrm{~min}$ in vitro compared with the isotype IgG treated control group (Fig. 2B).

Interaction of p300 with Aktl is increased in human NPC cells treated with $I L-17 A$. In order to investigate the potential mechanism underlying Akt1 acetylation, the expression of CBP, p300 and PCAF (three important acetyl transferases) (30-32) and the interaction of Akt1 with CBP, p300 and PCAF at the protein level were detected in C666-1 cells stimulated by IL-17A for $30 \mathrm{~min}$. It was demonstrated that IL-17A did not markedly enhance the lysate protein expression of CBP, p300 and PCAF in C666-1 cells compared with the corresponding untreated control groups (Fig. 3). However, the interaction of Akt1 with p300, but not with CBP or PCAF at the protein level, was revealed to be markedly enhanced in C666-1 cells in response to IL-17A stimulation compared with the untreated and isotype IgG control groups (Fig. 3). These results indicate that IL-17A stimulation enhances the interaction of p300 with Akt1 at the protein level in human NPC cells, suggesting a potential role of p300 in acetylating Akt1.

p300 is required for Akt1 acetylation in NPC cells by exposure to $I L-17 A$. In order to further determine the role of p300 in Akt1 acetylation and phosphorylation, C666-1 cells were treated with shRNA targeted against p300 for $48 \mathrm{~h}$, followed by IL-17A stimulation for $30 \mathrm{~min}$. The co-immunoprecipitation assay demonstrated that the shRNA knockdown of p300 significantly suppressed Aktl acetylation and phosphorylation in C666-1 cells exposed to IL-17A, compared with the corresponding shRNA control groups (Fig. 4), suggesting that the acetyltransferase activity of p300 is required for Akt1 acetylation and phosphorylation in NPC cells.

p300-mediated Aktl acetylation contributes to the proliferation of NPC cells stimulated by $I L-17 A$. Since p300 was revealed to be required for Akt1 acetylation in NPC cells by exposure to IL-17A (Fig. 4), the role of p300-mediated Akt1 acetylation in proliferation of NPC cells stimulated by IL-17A was further determined. The results demonstrated that the shRNA knockdown of p300 (Fig. 5A) or the blockade of Akt1 via Ly294002 treatment (Fig. 5B) could cause significant inhibition with regards to cellular proliferation in C666-1 cells treated with IL-17A. Taken together, the data indicate that p300-mediated Akt1 acetylation contribute to the proliferation of NPC cells stimulated by IL-17A.

\section{Discussion}

NPC is one of the most common types of malignancy in Southern China and Southeast Asia $(1,2)$. However, the molecular pathogenesis of NPC remains unclear. Recently, inflammatory response has been considered to serve an important role in the process of cancer development (33-36). Furthermore, the generation of cytokines, particularly IL-17A, has been demonstrated to serve an essential role in regulating inflammatory responses in vivo $(37,38)$ and contribute to cancer progression $(39,40)$. In the current study, the effect of IL-17A 


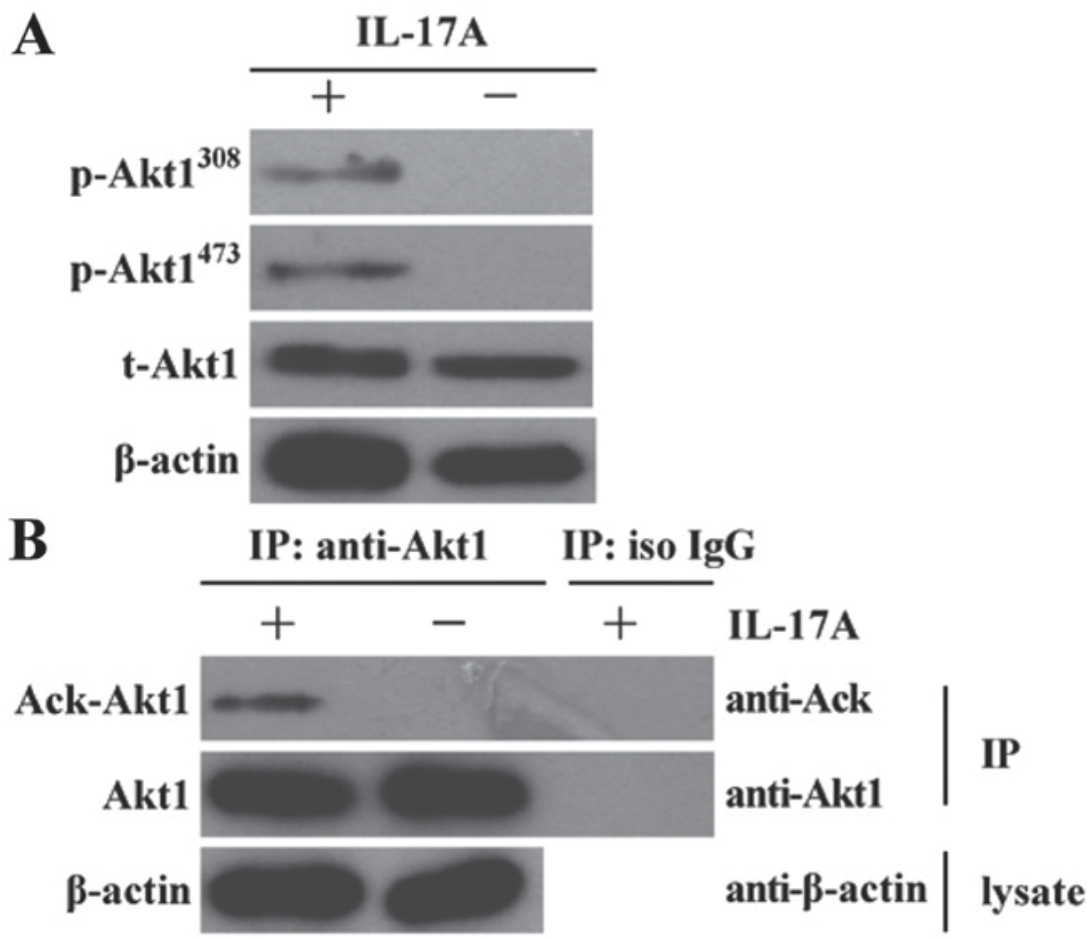

Figure 2. Effect of IL-17A on Akt1 phosphorylation and acetylation in nasopharyngeal carcinoma C666-1 cells. (A) C666-1 cells were stimulated with

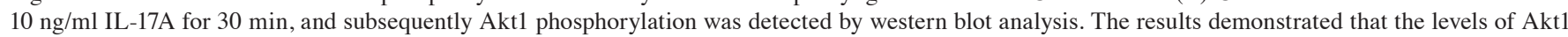
phosphorylation at the $\mathrm{Thr}^{308}$ and $\mathrm{Ser}^{473}$ sites were markedly increased in C666-1 cells induced by IL-17A. (B) C666-1 cells were incubated with $10 \mathrm{ng} / \mathrm{ml}$ IL-17A for $30 \mathrm{~min}$, and subsequently anti-Akt1 antibody and isotype control $\operatorname{IgG}$ were used respectively to perform immunoprecipitation following cell lysis. Subsequently, Ack-Akt and total Akt1 in immunoprecipitation complex were detected by western blot analysis. The results revealed that the level of Akt1 acetylation was markedly enhanced in C666-1 cells following stimulation with IL-17A compared with untreated control and iso IgG treated control groups. The data are from one experiment ( $\mathrm{n}=3$ in each group), and are representative of three independent experiments. Representative western blot photographs were produced. IL-17A, interleukin-17A; IgG, immunoglobulin G; Ack, acelytated; Akt1, AKT serine/threonine kinase 1; p, phosphorylated; t, total; iso, isotype; IP, immunoprecipitation.

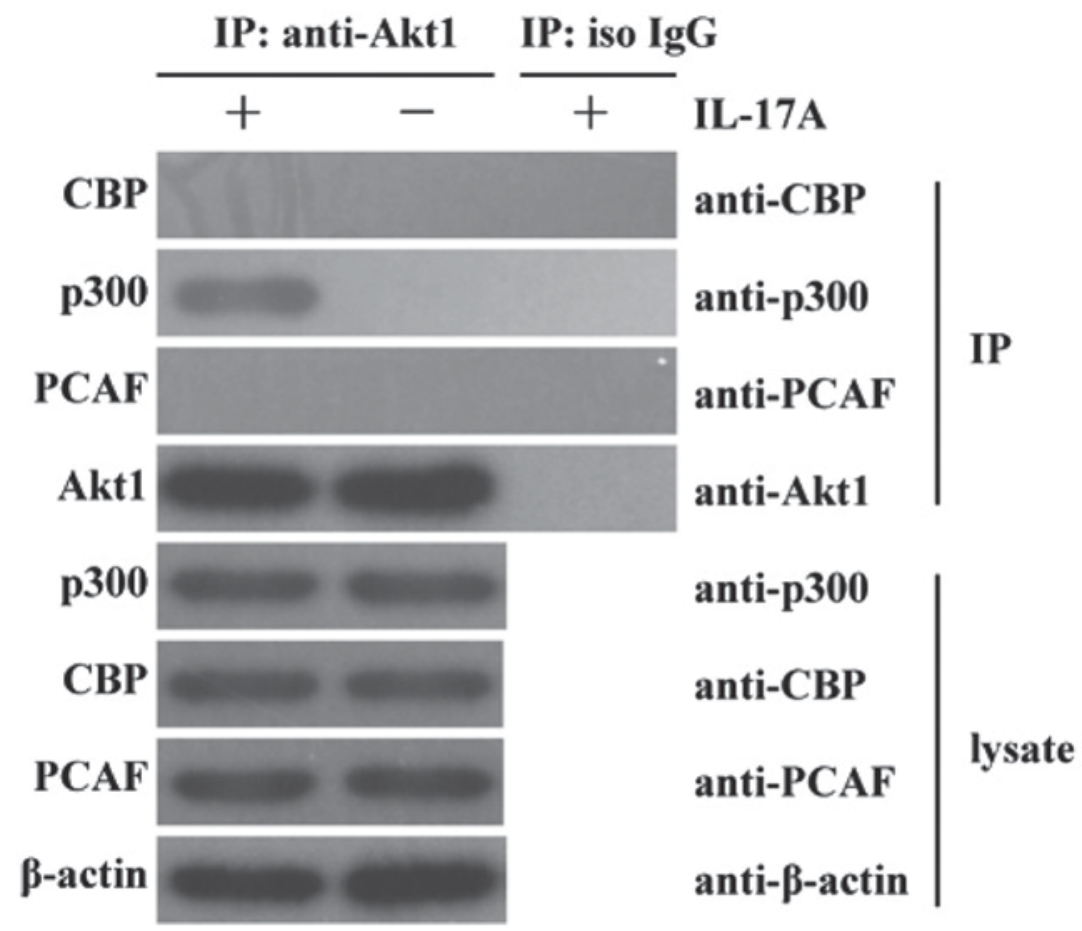

Figure 3. Association of Akt1 with p300 in IL-17A-treated nasopharyngeal carcinoma cells. C666-1 cells were stimulated with $10 \mathrm{ng} / \mathrm{ml} \mathrm{IL}-17 \mathrm{~A}$ for $30 \mathrm{~min}$. Western blot analysis revealed that the expression of p300, CBP and PCAF was not induced by IL-17A stimulation. Further co-immunoprecipitation analysis demonstrated that the interaction of Akt1 with p300, but not with CBP or PCAF, was induced in C666-1 cells in response to IL-17A stimulation for 30 min. The data are from one experiment ( $\mathrm{n}=3$ in each group), and are representative of three independent experiments. Representative western blot photographs were produced. IL-17A, interleukin-17A; IgG, immunoglobulin G; CBP, CREB-binding protein; p300, E1A binding protein p300; PCAF, p300/CBP-associated factor; Akt1, AKT serine/threonine kinase 1; iso, isotype; IP, immunoprecipitation. 

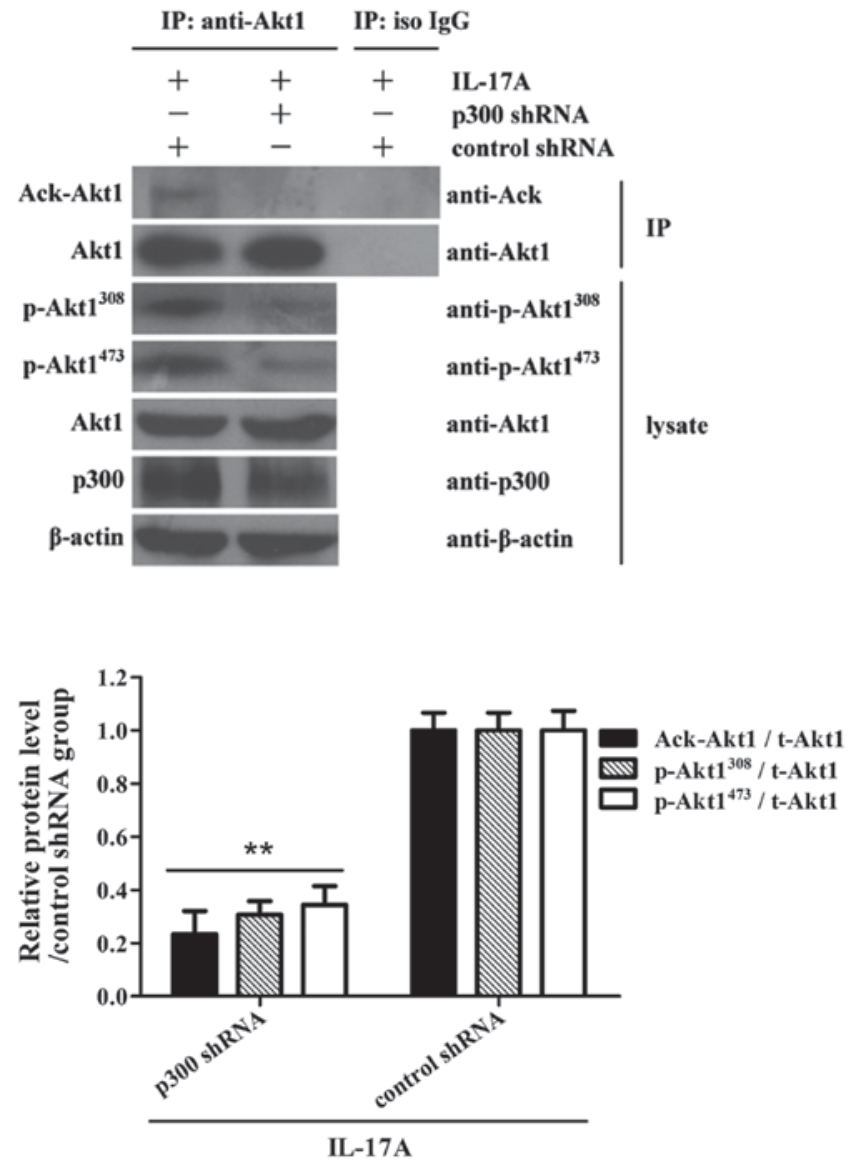

Figure 4. Role of p300 in Akt1 acetylation and phosphorylation in nasopharyngeal carcinoma cells following exposure to IL-17A. C666-1 cells were transfected with p300 shRNA or control shRNA for $48 \mathrm{~h}$ prior to IL-17A stimulation. Co-immunoprecipitation and western blot analysis were further used to detect Akt1 acetylation and phosphorylation at 30 min following IL-17A stimulation. The results showed that p300 shRNA suppressed Akt1 acetylation and phosphorylation in C666-1 cells following exposure to IL-17A compared to the control shRNA treatment. ${ }^{* *} \mathrm{P}<0.01$ vs. control shRNA+IL-17A group. The data are from one experiment, and are representative of three independent experiments. Results are presented as the mean \pm standard deviation ( $\mathrm{n}=3$ in each group). Representative western blot photographs were produced. IL-17A, interleukin-17A; IgG, immunoglobulin G; Ack, acelytated; Akt1, AKT serine/threonine kinase 1; $\mathrm{p}$, phosphorylated; t, total; iso, isotype; IP, immunoprecipitation; p300, E1A binding protein $\mathrm{p} 300$; sh, short hairpin.

in the proliferation of human NPC cells was initially evaluated. It was revealed that IL-17A in vitro was able to enhance the proliferation of human NPC cells. Further investigation revealed that blockade of the IL-17A receptor was able to inhibit IL-17A-triggered NPC cell proliferation. These results indicate that an overproduction of IL-17A may contribute to the proliferation of human NPC cells. Notably, Li et al (41) identified that tumor microenvironment macrophage inhibitory factor directs the accumulation of IL-17-producing tumor-infiltrating lymphocytes and predicts favorable survival in patients with NPC. However, the results of the present study suggest that IL-17A directly promotes the proliferation of human NPC cells. One possible explanation is that tumor microenvironment macrophages inhibit NPC growth via other mechanisms, although they may promote the accumulation of IL-17-producing tumor-infiltrating lymphocytes within NPC tumor tissue.
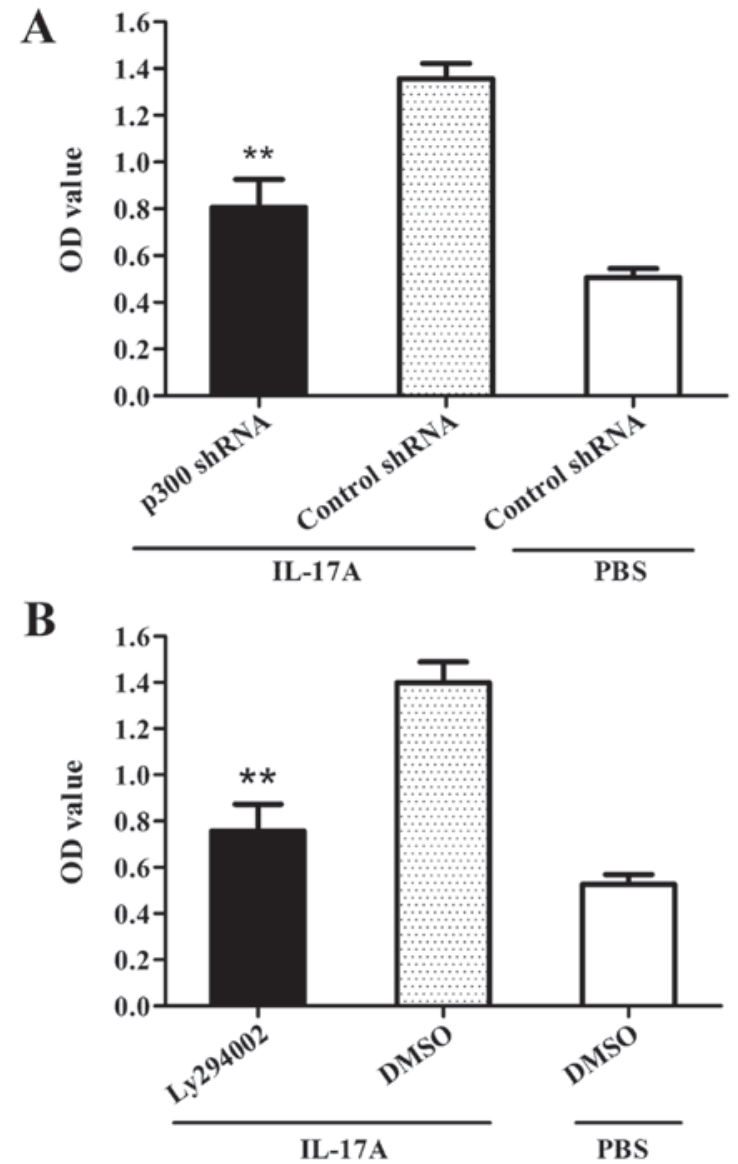

Figure 5. Role of p300-mediated Akt1 acetylation in the proliferation of nasopharyngeal carcinoma cells stimulated by IL-17A. (A) C666-1 cells were transfected with p300 shRNA or control shRNA for $48 \mathrm{~h}$, followed by IL-17A stimulation for an additional $48 \mathrm{~h}$, and cell proliferation was detected by CCK- 8 assay. The results showed that p300 shRNA treatment was able to inhibit the proliferation of C666-1 cells induced by IL-17A compared to control shRNA treatment. ${ }^{* *} \mathrm{P}<0.01$ vs. control shRNA+IL-17A group. (B) CCK-8 analysis revealed that C666-1 cells treated with the protein inhibitor Ly294002 for 30 min exhibited reduced cellular proliferation in response to IL-17A stimulation for $48 \mathrm{~h}$ compared to C666-1 cells treated with DMSO. ${ }^{* *} \mathrm{P}<0.01$ vs. DMSO+IL-17A group. The data are from one experiment, and are representative of three independent experiments. Results are presented as the mean \pm standard deviation ( $\mathrm{n}=3$ in each group). sh, short hairpin; OD, optical density; p300, E1A binding protein p300; DMSO, dimethyl sulfoxide; IL-17A, interleukin-17A; Akt1, AKT serine/threonine kinase 1.

The proliferation of cancer cells is regulated by a complex array of signaling pathways $(42,43)$. Among these signaling pathways, the activation of Akt1 is involved in proliferative and anti-apoptotic effects in NPC $(44,45)$. Therefore, in the present study, Akt1 phosphorylation was further measured in NPC cells stimulated with IL-17A. The data revealed that Akt1 phosphorylation was increased in NPC cells treated with IL-17A compared with the untreated control group. However, the mechanism underlying the regulation of Akt1 phosphorylation remains elusive. Given that Akt1 is able to undergo acetylation, which is an essential regulatory mehcanism required for Akt phosphorylation and subsequent activation (27), Aktl acetylation was further measured in NPC cells stimulated by IL-17A. The results of the present study demonstrated that the level of Akt1 acetylation was markedly elevated in human NPC cells treated with IL-17A compared with the isotype $\operatorname{IgG}$ treated control group. 
Since Akt1 acetylation was markedly enhanced in human NPC cells treated with IL-17A, further experiments were designed to investigate the mechanism of Akt1 acetylation. It is well accepted that CBP, p300 and PCAF possess acetyl transferase activity and serve direct roles in the regulation of transcription factor and signaling molecule activity (30-32). Therefore, the roles of CBP, p300 and PCAF in Akt1 acetylation were investigated in C666-1 cells treated with IL-17A. The results revealed that the interaction of Akt1 with p300, but not $\mathrm{CBP}$ and PCAF at the protein level, was enhanced in C666-1 cells in response to IL-17A stimulation. In addition, p300 silencing suppressed Akt1 acetylation and phosphorylation, and the cellular proliferation of NPC cells in response to IL-17A. These results indicate that p300-mediated Akt1 acetylation is important for Akt1 activation and cellular proliferation in human NPC cells induced by IL-17A. Since Akt activation is regulated by a complex mechanism including phosphorylation, ubiquitination, SUMOylation and acetylation $(27,46,47)$, further studies are required to investigate the potential interaction of these modifications in human NPC cells exposed to IL-17A.

In conclusion, the results of the current study revealed that IL-17A could stimulate the proliferation of human NPC cells in vitro. Furthermore, it was demonstrated that $\mathrm{p} 300$-mediated Akt1 acetylation was involved in the proliferation of human NPC cells in response to IL-17A. These results may provide a potential strategy for treating patients with NPC through the inhibition of IL-17A or its receptors.

\section{Acknowledgements}

The authors would like to thank Dr Lei Shi (The First People's Hospital of Kunshan affiliated with Jiangsu University, Zhenjiang, China) for providing the pcDNA3.1/Akt1-His plasmid.

\section{References}

1. Yan M, Zhang Y, He B, Xiang J, Wang ZF, Zheng FM, Xu J, Chen MY, Zhu YL, Wen HJ, et al: IKKa restoration via EZH2 suppression induces nasopharyngeal carcinoma differentiation. Nat Commun 5: 3661, 2014.

2. Du XJ, Tang LL, Mao YP, Sun Y, Zeng MS, Kang TB, Jia WH, Lin AH and Ma J: The pretreatment albumin to globulin ratio has predictive value for long-term mortality in nasopharyngeal carcinoma. PLoS One 9: e94473, 2014.

3. Xu T, Fan B, Lv C and Xiao D: Slug mediates nasopharyngeal carcinoma radioresistance via downregulation of PUMA in a p53-dependent and -independent manner. Oncol Rep 33: 2631-2638, 2015.

4. Zuo Y, Liao S, Xu Z, Xie J, Huang W and Yu Z: A new version of targeted minicircle producer system for EBV-positive human nasopharyngeal carcinoma. Oncol Rep 32: 2564-2570, 2014.

5. Edefonti V, Nicolussi F, Polesel J, Bravi F, Bosetti C, Garavello W, La Vecchia C, Bidoli E, Decarli A, Serraino D, et al: Nutrient-based dietary patterns and nasopharyngeal cancer: Evidence from an exploratory factor analysis. Br J Cancer 112: 446-454, 2015.

6. Punkenburg E, Vogler T, Büttner M, Amann K, Waldner M, Atreya R, Abendroth B, Mudter J, Merkel S, Gallmeier E, et al: Batf-dependent Th17 cells critically regulate IL-23 driven colitis-associated colon cancer. Gut 65: 1139-1150, 2016.

7. Prado-Garcia H, Romero-Garcia S, Rumbo-Nava U and Lopez-Gonzalez JS: Predominance of th17 over regulatory T-cells in pleural effusions of patients with lung cancer implicates a proinflammatory profile. Anticancer Res 35: 1529-1535, 2015.
8. Paladugu M, Thakur A, Lum LG, Mittal S and Parajuli P: Generation and immunologic functions of Th17 cells in malignant gliomas. Cancer Immunol Immunother 62: 75-86, 2013.

9. Wang L, Ma R, Kang Z, Zhang Y, Ding H, Guo W, Gao Q and $\mathrm{Xu}$ M: Effect of IL-17A on the migration and invasion of NPC cells and related mechanisms. PLoS One 9: e108060, 2014.

10. House CD, Wang BD, Ceniccola K, Williams R, Simaan M, Olender J, Patel V, Baptista-Hon DT, Annunziata CM, Gutkind JS, et al: Voltage-gated Na+ channel activity increases colon cancer transcriptional activity and invasion via persistent MAPK signaling. Sci Rep 5: 11541, 2015.

11. Yuan J, Liu M, Yang L, Tu G, Zhu Q, Chen M, Cheng H, Luo H, $\mathrm{Fu} \mathrm{W,} \mathrm{Li} \mathrm{Z} \mathrm{and} \mathrm{Yang} \mathrm{G:} \mathrm{Acquisition} \mathrm{of} \mathrm{epithelial-mesenchymal}$ transition phenotype in the tamoxifen-resistant breast cancer cell: A new role for $G$ protein-coupled estrogen receptor in mediating tamoxifen resistance through cancer-associated fibroblast-derived fibronectin and $\beta 1$-integrin signaling pathway in tumor cells. Breast Cancer Res 17: 69, 2015.

12. Wen W, Wu J, Liu L, Tian Y, Buettner R, Hsieh MY, Horne D, Dellinger TH, Han ES, Jove R and Yim JH: Synergistic anti-tumor effect of combined inhibition of EGFR and JAK/STAT3 pathways in human ovarian cancer. Mol Cancer 14: 100, 2015.

13. Zhang P, Guo X, Li J, Yu S, Wang L, Jiang G, Yang D, Wei Z, Zhang N, Liu J and Sun Y: Immunoglobulin-like transcript 4 promotes tumor progression and metastasis and up-regulates VEGF-C expression via ERK signaling pathway in non-small cell lung cancer. Oncotarget 6: 13550-13563, 2015.

14. Huang W, Liu J, Feng X, Chen H, Zeng L, Huang G, Liu W, Wang L, Jia W, Chen J and Ren C: DLC-1 induces mitochondrial apoptosis and epithelial mesenchymal transition arrest in nasopharyngeal carcinoma by targeting EGFR/Akt/NF- $\kappa \mathrm{B}$ pathway. Med Oncol 32: 115, 2015.

15. Qin J, Ji J, Deng R, Tang J, Yang F, Feng GK, Chen WD, Wu XQ, Qian XJ, Ding K and Zhu XF: DC120, a novel AKT inhibitor, preferentially suppresses nasopharyngeal carcinoma cancer stem-like cells by downregulating Sox2. Oncotarget 6: 6944-6958, 2015.

16. Xu T, Su B, Wang C, Wang S, Huang H, Pan Y, Wang D, Wei W, Claret FX and Yang H: Molecular markers to assess short-term disease local recurrence in nasopharyngeal carcinoma. Oncol Rep 33: 1418-1426, 2015.

17. Zhang M, Zhou X and Zhou K: Resveratrol inhibits human nasopharyngeal carcinoma cell growth via blocking pAkt/p70S6K signaling pathways. Int J Mol Med 31: 621-627, 2013.

18. Joglekar M, Elbazanti WO, Weitzman MD, Lehman HL and van Golen KL: Caveolin-1 mediates inflammatory breast cancer cell invasion via the Akt1 pathway and RhoC GTPase. J Cell Biochem 16: 923-933, 2015.

19. Zhou H, Wei J, Dai Q, Wang L, Luo J, Cheang T and Wang S: CaCO3/CaIP6 composite nanoparticles effectively deliver AKT1 small interfering RNA to inhibit human breast cancer growth. Int J Nanomedicine 10: 4255-4266, 2015.

20. Chiu CT, Chen JH, Chou FP and Lin HH: Hibiscus sabdariffa leaf extract inhibits human prostate cancer cell invasion via down-regulation of Akt/NF-kB/MMP-9 pathway. Nutrients 7: 5065-5087, 2015.

21. Qian D, Chen K, Deng H, Rao H, Huang H, Liao Y, Sun X, Lu S, Yuan Z, Xie D and Cai Q: MicroRNA-374b suppresses proliferation and promotes apoptosis in T-cell lymphoblastic lymphoma by repressing AKT1 and Wnt-16. Clin Cancer Res 21: 4881-4891, 2015.

22. Webster BR, Scott I, Han K, Li JH, Lu Z, Stevens MV, Malide D, Chen Y, Samsel L, Connelly PS, et al: Restricted mitochondrial protein acetylation initiates mitochondrial autophagy. J Cell Sci 126: 4843-4849, 2013.

23. Karthik S, Sankar R, Varunkumar K, Anusha C and Ravikumar V: Blocking NF- $\kappa \mathrm{B}$ sensitizes non-small cell lung cancer cells to histone deacetylase inhibitor induced extrinsic apoptosis through generation of reactive oxygen species. Biomed Pharmacother 69: 337-344, 2015.

24. Kim HJ, Joe Y, Yu JK, Chen Y, Jeong SO, Mani N, Cho GJ, Pae HO, Ryter SW and Chung HT: Carbon monoxide protects against hepatic ischemia/reperfusion injury by modulating the miR-34a/SIRT1 pathway. Biochim Biophys Acta 1852: $1550-1559,2015$.

25. Ansari MA, Dutta S, Veettil MV, Dutta D, Iqbal J, Kumar B, Roy A, Chikoti L, Singh VV and Chandran B: Herpesvirus genome recognition induced acetylation of nuclear IFI16 is essential for its cytoplasmic translocation, inflammasome and IFN- $\beta$ responses. PLoS Pathog 11: e1005019, 2015. 
26. Yang H,Zhou L, Shi Q, Zhao Y, Lin H, Zhang M, Zhao S, Yang Y, Ling ZQ, Guan KL, et al: SIRT3-dependent GOT2 acetylation status affects the malate-aspartate NADH shuttle activity and pancreatic tumor growth. EMBO J 34: 1110-1125, 2015.

27. Zhang S, Sun G, Wang Z, Wan Y, Guo J and Shi L: PCAF-mediated Aktl acetylation enhances the proliferation of human glioblastoma cells. Tumour Biol 36: 1455-1462, 2015.

28. Cai K, Wan Y, Wang Z, Wang Y, Zhao X and Bao X: C5a promotes the proliferation of human nasopharyngeal carcinoma cells through PCAF-mediated STAT3 acetylation. Oncol Rep 32: 2260-2266, 2014.

29. Liu Y, Li Z, Wu L, Wang X, Yu Y, Zhao Q and Luo F: MiRNA-125a-5p: A regulator and predictor of gefitinib's effect on nasopharyngeal carcinoma. Cancer Cell Int 14: 24, 2014.

30. Zhu LH, Sun LH, Hu YL, Jiang Y, Liu HY, Shen XY, Jin XY, Zhen X, Sun HX and Yan GJ: PCAF impairs endometrial receptivity and embryo implantation by down-regulating $\beta 3$-integrin expression via HOXA10 acetylation. J Clin Endocrinol Metab 98: 4417-4428, 2013

31. Qiu W, Zhou J, Zhu G, Zhao D, He F, Zhang J, Lu Y, Yu T, Liu L and Wang Y: Sublytic C5b-9 triggers glomerular mesangial cell apoptosis via XAF1 gene activation mediated by $\mathrm{p} 300$-dependent IRF-1 acetylation. Cell Death Dis 5: e1176, 2014.

32. Ma B, Fey M and Hottiger MO: WNT/ $\beta$-catenin signaling inhibits CBP-mediated RelA acetylation and expression of proinflammatory NF-кB target genes. J Cell Sci 128: 2430-2436, 2015.

33. Sun Y, Zhu D, Wang G, Wang D, Zhou H, Liu X, Jiang M Liao L, Zhou Z and Hu J: Pro-inflammatory cytokine IL-1ß Up-regulates CXC chemokine receptor 4 via Notch and ERK signaling pathways in tongue squamous cell carcinoma. PLoS One 10: e0132677, 2015.

34. Mishra A, Sullivan L and Caligiuri MA: Molecular pathways: Interleukin-15 signaling in health and in cancer. Clin Cancer Res 20: 2044-2050, 2014

35. Koh SJ, Kim JM, Kim IK, Ko SH and Kim JS: Anti-inflammatory mechanism of metformin and its effects in intestinal inflammation and colitis-associated colon cancer. J Gastroenterol Hepatol 29: 502-510, 2014.

36. Li Z, Duan Y, Cheng S, Chen Y, Hu Y, Zhang L, He J, Liao Q, Yang L and Sun LQ: EBV-encoded RNA via TLR3 induces inflammation in nasopharyngeal carcinoma. Oncotarget 6: 24291-25303, 2015.

37. Sjökvist Ottsjö L, Flach CF, Nilsson S, Malefyt Rde W, Walduck AK and Raghavan S: Defining the roles of IFN- $\gamma$ and IL-17A in inflammation and protection against helicobacter pylori infection. PLoS One 10: e0131444, 2015.
38. Dai H, Xu L, Tang Y, Liu Z and Sun T: Treatment with a neutralising anti-rat interleukin-17 antibody after multiple-trauma reduces lung inflammation. Injury 46: 1465-1470, 2015.

39. Gu K, Li MM, Shen J, Liu F, Cao JY, Jin S and Yu Y: Interleukin-17-induced EMT promotes lung cancer cell migration and invasion via NF- $\kappa \mathrm{B} / \mathrm{ZEB} 1$ signal pathway. Am J Cancer Res 5: 1169-1179, 2015.

40. Mombelli S, Cochaud S, Merrouche Y, Garbar C, Antonicelli F, Laprevotte E, Alberici G, Bonnefoy N, Eliaou JF, Bastid J, et al: IL-17A and its homologs IL-25/IL-17E recruit the c-RAF/S6 kinase pathway and the generation of pro-oncogenic LMW-E in breast cancer cells. Sci Rep 5: 11874, 2015.

41. Li J, Mo HY, Xiong G, Zhang L, He J, Huang ZF, Liu ZW, Chen QY, Du ZM, Zheng LM, et al: Tumor microenvironment macrophage inhibitory factor directs the accumulation of interleukin-17-producing tumor-infiltrating lymphocytes and predicts favorable survival in nasopharyngeal carcinoma patients. J Biol Chem 287: 35484-35495, 2012.

42. Xiao W, Chen X and He M: Inhibition of the Jagged/Notch pathway inhibits retinoblastoma cell proliferation via suppressing the PI3K/Akt, Src, p38MAPK and Wnt/ $\beta$-catenin signaling pathways. Mol Med Rep 10: 453-458, 2014.

43. Hsu FT, Liu YC, Chiang IT, Liu RS, Wang HE, Lin WJ and Hwang JJ: Sorafenib increases efficacy of vorinostat against human hepatocellular carcinoma through transduction inhibition of vorinostat-induced ERK/NF- $\kappa \mathrm{B}$ signaling. Int J Oncol 45: 177-188, 2014.

44. Zheng D, Zhu G, Liao S, Yi W, Luo G, He J, Pei Z, Li G and Zhou Y: Dysregulation of the PI3K/Akt signaling pathway affects cell cycle and apoptosis of side population cells in nasopharyngeal carcinoma. Oncol Lett 10: 182-188, 2015.

45. Cheung AK, Ip JC, Chu AC, Cheng Y, Leong MM, Ko JM, Shuen WH, Lung HL and Lung ML: PTPRG suppresses tumor growth and invasion via inhibition of Akt signaling in nasopharyngeal carcinoma. Oncotarget 6: 13434-13447, 2015.

46. Li R, Wei J, Jiang C, Liu D, Deng L, Zhang K and Wang P: Akt SUMOylation regulates cell proliferation and tumorigenesis. Cancer Res 73: 5742-5753, 2013.

47. Chan CH, Li CF, Yang WL, Gao Y, Lee SW, Feng Z, Huang HY, Tsai KK, Flores LG, Shao Y, et al: The Skp2-SCF E3 ligase regulates Akt ubiquitination, glycolysis, herceptin sensitivity, and tumorigenesis. Cell 149: 1098-1111, 2012. 